\title{
ALGEPS
}

REVISTA DE GEOLOGIA, SÈRIE B no 627 - Abril del 2013

ISSN $1132-7014$

D.L.B. 28.178 - 92

14 pàgines

\section{RECORREGUT GEOLÒGIC I MINERALÒGIC PER LES COMARQUES DE LA RIBERA D’EBRE I TERRA ALTA: DES DE GANDESA A VINEBRE, MORA LA NOVA I A MIRAVET}

Josep M. Mata-Perelló i Joaquim Sanz Balagué 



\section{RECORREGUT GEOLÒGIC I MINERALÒGIC PER LES COMARQUES DE LA RIBERA D'EBRE I TERRA ALTA: DES DE GANDESA A VINEBRE, MORA LA NOVA I A MIRAVET}

Per Josep M. MATA-PERELLÓ

\section{ADVERTIMENTS PREVIS}

Com en altres recorreguts de RECERCA GEOLÒGICA I MINERALÒGICA ..., si es disposa del temps suficient, poden efectuar-se passant per totes les parades i filloles. En cas contrari, recomanem prescindir de les anomenades PARADES - CONDICIONALS.

També recomanem de cercar la informació més adient, sobre els trams a recórrer mitjançant camins de terra, o de pista. També serà bo tenir informació sobre el "pas de barca", per tal d'arribar a Miravet, passant l'Ebre.

Per d'altra banda, recomanem tenir una cura extrema de la NATURA, evitant qualsevol forma d'agressió sobre ella, o de fer-n'hi un mal ús del que en ofereix la nostra mare Terra.

\section{BREU INTRODUCCIÓ}

En aquesta ocasió, el recorregut del present itinerari discorrerà per una zona en la qual conflueixen tres unitats geològiques netament diferenciades: la Depressió Geològica de l'Ebre, la Serralada Prelitoral Catalana (integrant del Sistema Mediterrani), i la Serralada Ibèrica. Tot i així, els primers trams es faran per la Depressió Geològica de l'Ebre i tot seguit per la Branca Externa de la Serralada Prelitoral Catalana i per la Depressió de Mora (situades ambdues dintre del Sistema Mediterrani).

Així, en iniciar-se el recorregut a la població de Gandesa, ho farem a la primera unitat geològica esmentada, a la Depressió Geològica de l'Ebre. D’aquesta manera, els primers trams, entre la població abans esmentada i el Pas de l'Ase, śefectuaran per aquesta unitat geològica.

Immediatament després, el recorregut transitarà per la Serralada Prelitoral Catalana (concretament per la denominada Branca Externa), arribant en aquest tram molt a prop de Garcia, a la denominada Depressió de Mora (la qual es troba dintre del Sistema Mediterrani, com l'anterior). Per aquesta unitat geològica s'arribarà primer a les immediacions de Miravet, per on es tocarà la Serralada Prelitoral Catalana (però ara la 
seva Branca Interna). En aquest indret finalitzarà el recorregut de 1'Itinerari, molt prop del contacte entre aquesta i la ja esmentada Depressió de Mora.

Per d'altra banda, el recorregut de l'itinerari, discorrerà fonamentalment per dues de les comarques que formen part de les Terres de l'Ebre o Regió de Tortosa, concretament per la del la Terra Alta i per la de la Ribera d'Ebre.

\section{OBJECTIUS FONAMENTALS D’AQUEST ITINERARI}

Els objectius fonamentals que es pretenen aconseguir en aquest itinerari, es poden concretar en els següents aspectes generals:

1.- Observació i descripció dels materials terciaris (de 1'Eocè i de l'Oligocè) de la Depressió Geològica de l'Ebre, que pertanyen majoritàriament al complex al-luvial de Gandesa - Horta de Sant Joan, que inclou, entre altres a la Formació Montsant i a la Formació Flix. Aquests materials, els anirem trobant als primers indrets del recorregut de l'itinerari, entre Gandesa i el Pas de l'Ase. També els trobarem entre Garcia i Miravet.

2.- Observació i descripció dels materials mesozoics (del Triàsic, del Juràssic i del Cretàcic), que constitueixen la Serralada Prelitoral del Sistema Mediterrani (a la seva Branca Externa). Aquests materials els trobarem entre Vinebre i García.

3.- Observació i descripció dels materials mesozoic (del Triàsic, del Juràssic i del Cretàcic), que constitueixen la Branca Interna de la Serralada Prelitoral del Sistema Mediterrani. Aquests materials els trobarem pels voltants de Miravet. de Mora.

4.- Observació dels mantells al·luvials quaternaris que reblen part de la Depressió

5.- Observació de les estructures locals d'aquests materials, al llarg del recorregut de l'itinerari, i de les relacions existents entre les dues unitats geològiques acabades d'esmentar. Així:

5A) de l'estructura de la Depressió Geològica de l'Ebre, que veurem als primers trams del recorregut. Dintre d'aquesta unitat, veurem la important discordança progressiva, que trobarem a la sortida septentrional del Pas de l'Ase, relacionada amb el contacte d'aquesta unitat amb la Serralada Prelitoral Catalana

5B) de l'estructura de Branca Externa de la Serralada Prelitoral Catalana (integrant del Sistema Mediterrani), que trobarem a diferents trams del recorregut. En molts indrets, aquests es troben prop de la seva Zona d'Enllaç amb el Sistema Ibèric.

5C) de la Depressió de Mora (ubicada entre les dues branques de la Serralada Prelitoral Catalana del Sistema Mediterrani), que trobarem entre Garcia i Miravet.

4D) de l'estructura de la Branca Interna de la Serralada Prelitoral Catalana (integrant del Sistema Mediterrani), que trobarem exclusivament pels voltants de la població de Miravet.

6.- Observació de les explotacions mineres relacionades amb les mineralitzacions anteriors, en especial de les relacionades amb les formacions guixoses, que trobarem al terme de Garcia, relacionades amb els afloraments del Keuper. 
7.- Observació i anàlisi dels impactes produïts sobre el Medi Natural (i sobre el Medi Ambient), tant per les explotacions mineres anteriors, com per altres activitats humanes.

8.- Observació dels diferents indrets relacionats amb el Patrimoni Geològic i Miner, que trobarem al llarg del recorregut. En aquest sentit, cal parlar del Pas de l'Ase i sobretot de la discordança progressiva de Vinebre - la Torre de l'Espanyol.

\section{ANTECEDENTS BIBLIOGRÀFICS}

Pel que fa al recorregut del present itinerari, existeixen alguns antecedents molt propers, obra del mateix autor del present itinerari. Es tracta de MATA-PERELLÓ (1989, 1995, 1996b, 1997a, 1997, 2000a, 2000b, 2000c, 2001a, 2001b, 2001c, 2001d, 2006a i 2006b). Un altre antecedent parcial, obra del mateix autor, es troba a MATA-PERELLÓ (1989), i correspon a un altre itinerari. Un altre antecedent molt immediat és el MATAPERELLÓ i ARASA (2004), en un itinerari força semblant al present.

Pel que fa a la descripció de les mineralitzacions d’aquesta comarca, farem esment d'un altre treball del mateix autor, de MATA-PERELLÓ (1991), relatiu a les mineralitzacions catalanes en general. Uns altres antecedents, cal situar-los en MATAPERELLÓ (1995a i 1995b), relatius als inventaris mineralògics de les comarques de la Terra Alta i del Matarranya.

I, finalment, pel que fa a l'estructura geològica de la zona per la qual discorre l'itinerari, farem esment dels treballs de GUIMERÅ et altri (1982) i de RIBA et altri (1976). També, i dintre d'aquest apartat, també farem esment de diversos treballs de l'IGME (1972). Tots ells són relatius a diversos fulls geològics corresponents als indrets per on passarà el recorregut de l'itinerari.

Tots aquests treballs referenciats, i d'altres, figuren esmentats per ordre alfabètic a l'apartat dedicat a la BIBLIOGRAFIA.

\section{RECORREGUT DE L'ITINERARI}

El recorregut de l'itinerari començarà dintre de la comarca de la Terra Alta, concretament a la seva capital, la població de Gandesa, per on es farà la primera aturada. Tot seguit es dirigirà cap al poble d'Ascó, entrant a la Ribera d'Ebre. Tot seguit, el recorregut es dirigirà cap a Vinebre, entrant tot seguit al conegut i espectacular Pas de l'Ase, per on farem diverses aturades.

Posteriorment, s'arribarà a Garcia, des d'on s'anirà cap a la propera Mora la Nova, per on es farà una fillola i una parada, tot anant cap a Falset. Després, des de Mora la Nova es baixarà cap a Ginestar, anant després cap a Miravet, tot sobrepassant 1'Ebre pel conegut "pas de Barca". En aquest recorregut, efectuat íntegrament dintre de la 
comarca de la Ribera d'Ebre, efectuarem diverses aturades. Prop d'aquesta darrera població, finalitzarà el recorregut de l'itinerari.

\section{DESCRIPCIÓ DE L'ITINERARI}

Com de costum, estructurarem el recorregut de l'itinerari en una sèrie de PARADES, que tot seguit anirem veient. En cada una d'aquestes aturades farem un breu comentari (geològic o mineralògic, segons s'escaigui).

Cada una d'aquestes parades tindrà un número, i un topònim representatiu. Per d'altra banda, s'indicarà el nom del poble més proper, el municipi al qual pertany l'indret, $\mathrm{i}$ la comarca on es troba situat. Per d'altra banda, també indicarem en cada cas, i entre parèntesi, el full topogràfic on es troba l'aturada.

Finalment, cal dir que el recorregut de l'itinerari s śinclourà dintre dels següents dos fulls, del "Mapa Topográfico Nacional", realitzats a l'escala 1:50.000 per 1'"Instituto Geográfico y Catastral": 470 (dit de Gandesa), 471 (dit de Mora d’Ebre) i 496 (dit d’Horta de Sant Joan).

Així doncs, la relació de parades ordenades, que composen aquest itinerari geològic i mineralògic, és el següent:

PARADA 1 - CONDICIONAL. ESTACIÓ D'AUTOBUSOS, (terme municipal de Gandesa, comarca de la Terra Alta). (Full 470).

El recorregut del present itinerari, s'iniciarà a la població de Gandesa, la capital de la comarca de la Terra Alta, iniciant-se a la moderna Estació d’Autobusos de la població, la qual es troba tot sortint cap a Corbera de Terra Alta, junt al costat de la carretera $\mathrm{N}-420$.

Al respecte, cal dir que tant la població, com bona part del seu terme, es troba situat a la Depressió Geològica de 1'Ebre, molt a prop del contacte amb la Serralada Prelitoral, per la denominada Zona d'Enllaç amb el Sistema Ibèric. També cal recordar que l'esmentada serralada es troba al SE, al Sud i al SW d'on som, i es troba constituta pels relleus mesozoics de la Serra de Cavalls i els de la Serra de Pàndols.

Així, els materials que es troben en aquest indret són terciaris, i més concretament de l'Oligocè. Pertanyen, per d'altra banda, a la Formació Flix, que aquí forma part del Complex al·luvial de Gandesa - Horta de Sant Joan.

Els afloraments d'aquesta formació, es troben constituïts per nivells de calcolutites ocres $i$ de gresos, del mateix color, clarament continentals. Afloren amplament al Nord $i$ al $N E$ de Gandesa. Per d'altra banda, també cal dir que sovint, entre aquests materials es fan palesos paleocanals, com veurem més endavant prop de Bot. 


\section{PARADA 2. CARRETERA COMARCAL DE GANDESA CAP ASCÓ, (terme municipal d’Ascó, comarca de la Ribera d'Ebre). (Full 470).}

Des de la parada anterior, cal fer un recorregut tot seguint la carretera que es dirigeix cap a Corbera d'Ebre (i posteriorment cap a Mora d'Ebre, la N-420 / C-12B). Tot i així, en arribar a la Venta de Camposines, ens caldrà agafar la carretera pròpiament dita C-12B. Per aquesta carretera, en uns $9 \mathrm{Km}$, ens caldrà fer una nova aturada. Així, des de l'anterior, haurem recorregut uns $20 \mathrm{Km}$, per tal d'arribar fins aquí.

En aquest recorregut, des de la parada anterior, s'han anat trobant trobant els materials cenozoics que reblen la Depressió Geològica de l'Ebre. Aquest són també els que apareixen a l'indret de l'aturada. Aquests materials pertanyen a la Formació Flix, trobant-se constituïts per uns afloraments de materials gresencs i calcolutítics ocres, els quals pertanyen a la. I, precisament, aquests materials són els que es troben a l'indret de la parada, per on es fan força evidents els paleocanals.

Per d'altra banda. aquí es fan força palesos uns filonets de GUIX FIBRÒS, els quals tallen als materials abans esmentats, tot reblint diàclasis i plans d'estratificació. De vegades, la potència d'aquets filonets es força considerable de vegades: de $5 \mathrm{a} 15 \mathrm{~cm}$.

PARADA 3 - CONDICIONAL. GASOLINERA DE VINEBRE, (terme municipal de Vinebre, comarca de la Ribera d'Ebre). (Full 470).

Després de realitzar l'aturada anterior, cal acabar d'arribar al poble d'Ascó (per la carretera $C-12 B)$. En arribar-hi, ens caldrà agafar la carretera $C$-12, per tal d'anar cap a Vinebre. Després de sobrepassar el poble, ens caldrà arribar fins a la Gasolinera de Vinebre, on farem una nova aturada, després de recórrer uns $10 \mathrm{Km}$ des de la parada anterior.

La totalitat d'aquest recorregut, s'haurà efectuat entre els materials gresencs $i$ calcolutítics ocres, de la Formació Flix. Aquests materials són els que reblen, en aquest indret, la Depressió Geològica de 1'Ebre on ens trobem ara situats, tot i que molt prop de la seva vorera meridional.

Des d'aquest indret, es pot gaudir d'un bon lloc d'observació de la depressió que hem acabat d'esmentar.

\section{PARADA 4. AREA DE DESCANS DE L'ENTRADA SEPTENTRIONAL} AL PAS DE L'ASE (terme municipal de Vinebre, comarca de la Ribera d'Ebre). (Full 470).

Després de fer la parada anterior, cal anar cap l'indret del Pas de l'Ase. En arribar a l'Àrea de Descans de l'entrada septentrional, ens caldrà fer la present aturada, després de recórrer uns $3 \mathrm{Km}$, des de la parada anterior.

Els primers trams del recorregut, s'hauran efectuat entre els afloraments de la Formació Flix, ja esmentats anteriorment. Més endavant, ben prop de l'indret de la parada, 
es fan palesos uns nivells detrítics, els quals pertanyen a la Formació Montsant. Tots aquests materials pertanyen a la Depressió Geològica de l'Ebre, i es troben constituïts per trams de gresos (amb alguns de calcolutites) i amb freqüents paleocanals conglomeràtics. Aquests materials dibuixen una interessant discordança progressiva. FOTOGRAFIA 1.

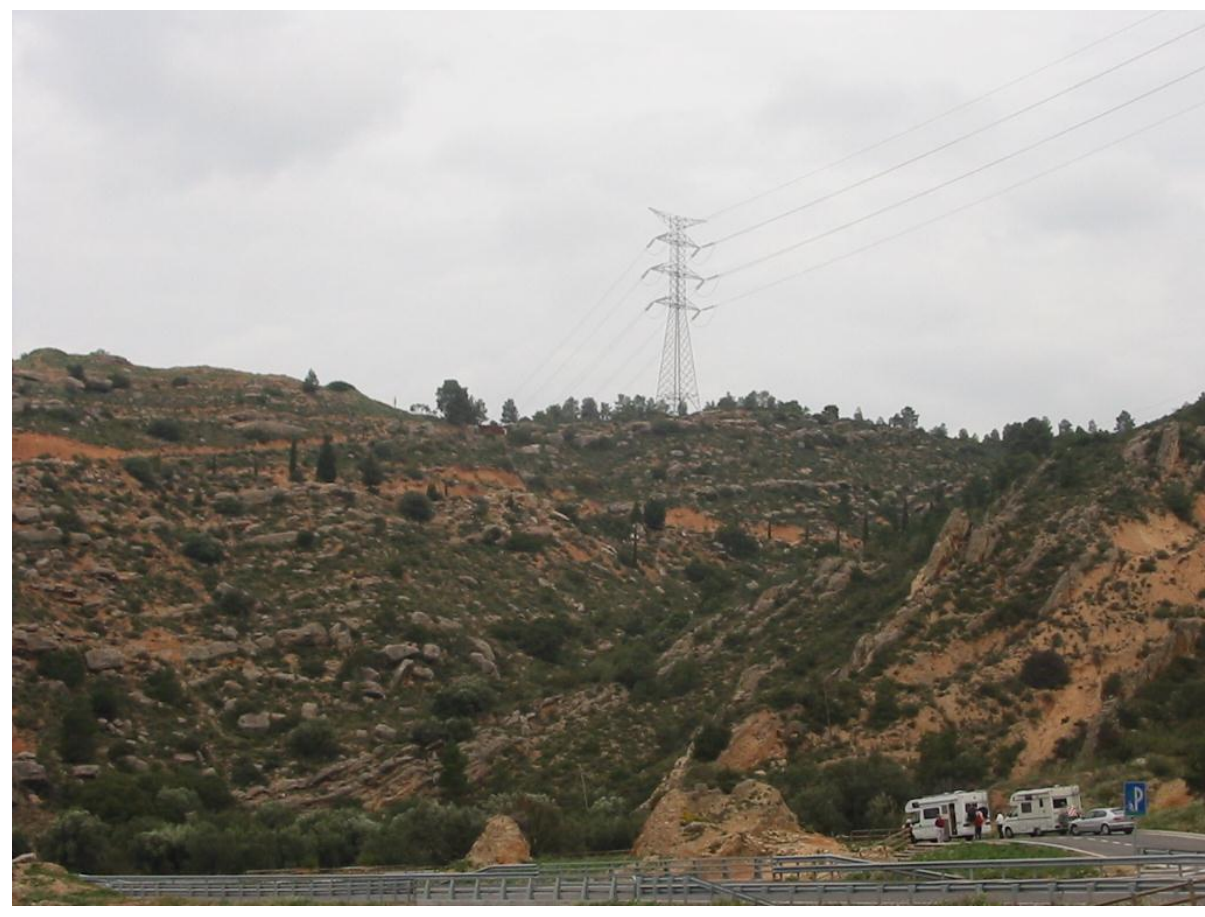

\section{FOTOGRAFIA 1}

Aspecte de la Discordança progressiva.

Els nivells que hi a tocar les rulottes estan molt inclinats; mentre els que hi ha sota les torres elèctriques són gairebé horitzontals

Tot seguit, i amb contacte discordant amb els anteriors, s'han començat a trobar uns afloraments carbonatats mesozoics cretàcics, els quals pertanyen a la Serralada Prelitoral Catalana del Sistema Mediterrani.

També cal fer esment, de que aquests materials carbonatats mesozoics cretàcics es troben força fracturats, fent-se palesos diferents plans de falla (sovint amb estries de desplaçament horitzontal).

També cal dir que precisament el riu Ebre, en travessar aquests materials carbonatats de la Serralada Prelitoral Catalana, dona lloc a un interessant estret, el denominat Pas de l’Ase, pel qual discorre tant la carretera com la línia del ferrocarril.

PARADA 5. CARRETERA A MORA, Km 2'5, PAS DE L'ASE, TRENCALL DE LA PEDRERA, (terme municipal de Garcia, comarca de la Ribera d’Ebre). (Full 470).

Des de la parada anterior, cal fer un breu recorregut tot seguint la carretera que es dirigeix cap a Garcia, la C-12. Per ella, després de fer un recorregut inferior als $2 \mathrm{Km}$, 
caldrà fer la present aturada. Així ara, en aquest lloc, ens trobem, al costat d'una caseta que hi al costat de la carretera, en un bon lloc per aparcar.

En aquest recorregut, des de la parada anterior, s' han continuat trobant els materials mesozoics esmentats a la parada anterior, de la Serralada Prelitoral del Sistema Mediterrani. En aquest indret, es fa clarament palès un sinclinal de doble vergència, per una part de "direcció catalana" (NE-SW), preponderant; i per d'altra de "direcció ibèrica" (NW-SE), que afecta a l'anterior.

Des d'aquest lloc, es pot fer una bona observació del Pas de l'Ase, obert per l'Ebre en travessar els materials carbonatats de la Serralada Prelitoral Catalana en aquest indret de la seva Branca Externa. FOTOGRAFIA 2.

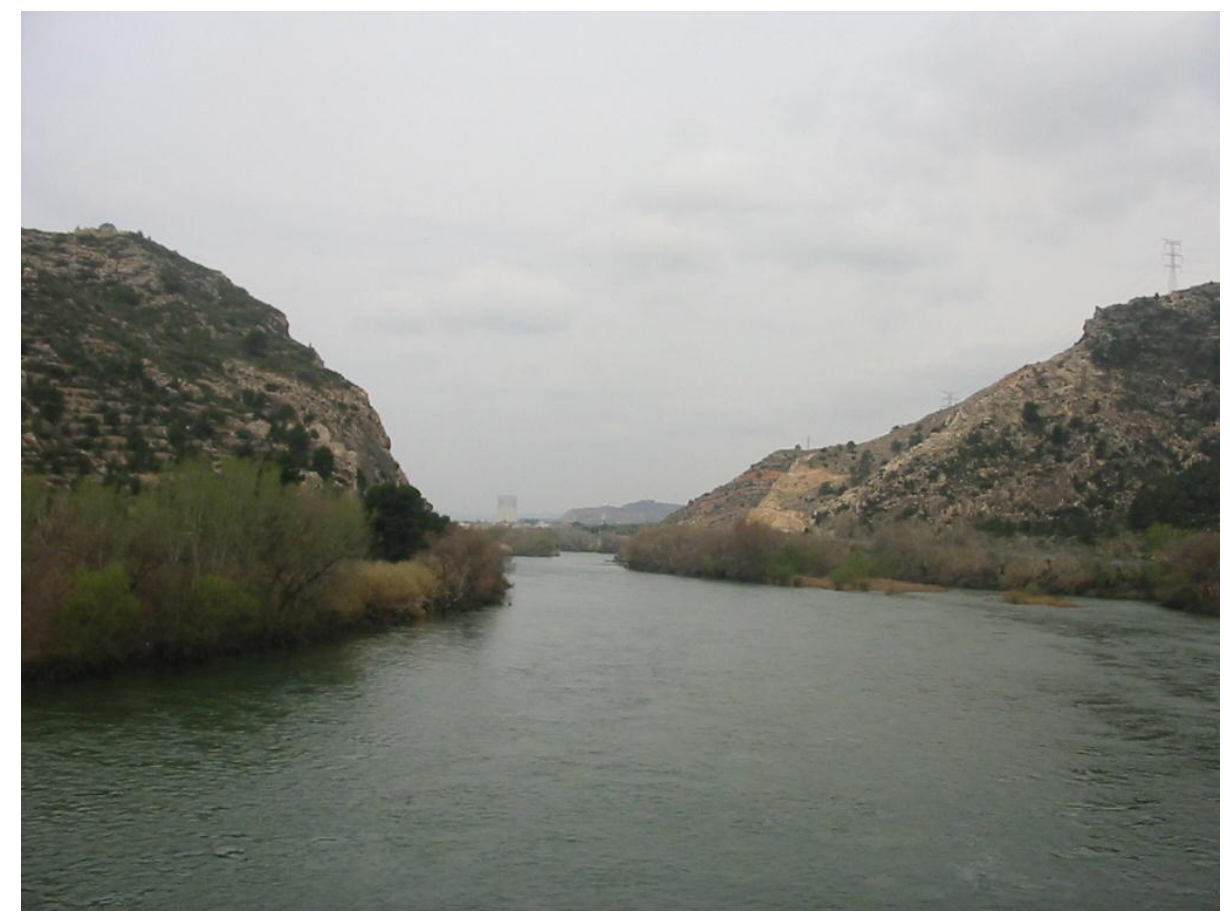

\section{FOTOGRAFIA 2}

Aspecte parcial del Pas de l'Ase, per la seva part septentrional. $\mathrm{Al}$ fons es veu la Torre de Refrigeració de la Central Nuclear d'Ascó

Per d'altra bada, des d'on som ara, eix un brancal que es dirigeix cap a una propera pedrera, on s'explotaven les calcàries mesozoiques del Cretàcic, per tal d'ésser emprades com a àrids per a la construcció.

PARADA 6 - CONDICIONAL. CARRETERA A MORA, PAS DE L'ASE, CAMÍ DE LA GUIXERA DE GARCIA, (terme municipal de Garcia, comarca de la Ribera d'Ebre). (Full 470).

Des de la parada anterior, cal fer un breu recorregut tot seguint la carretera que es dirigeix cap a Garcia. Per ella, després de fer un recorregut inferior als $2 \mathrm{Km}$, caldrà 
fer la present aturada, just d'on eix el camí que es dirigeix cap a una antiga guixera, situada a l'esquerra de la carretera.

En aquest recorregut, des de la parada anterior, s'han continuat trobant els materials mesozoics esmentats a la parada anterior, de la Serralada Prelitoral del Sistema Mediterrani. Tot i així, cap els voltants dels $2 \mathrm{Km}$ abans d'arribar a Garcia, s'han trobat uns afloraments dels nivells argilosos i guixosos que pertanyen al Triàsic Superior (al Keuper).

Precisament, en aquest indret hi va haver una guixera, on es van explotar aquests materials guixosos. Actualment es troba totalment aturada i quasi perduda.

\section{PARADA 7 - CONDICIONAL. ESTACIÓ DE LA RENFE DE MORA LA NOVA, (terme municipal de Mora la Nova, comarca de la Ribera d'Ebre). (Full 471).}

Des de la parada anterior cal anar cap al Sud, seguint sempre per la carretera $C$ 12. Així, aviat es passarà per Garcia i es deixarà el trencall del Molar, per l'esquerra. Finalment s'arribarà la població de Mora la Nova, que caldrà travessar, en arribar-hi, si s'escau podem anar cap als voltants de l'Estació de la RENFE. En aquest indret podem fer una nova aturada, després de recórrer uns $8 \mathrm{Km}$ més, des de l'anterior.

En aquest recorregut, hem anat circulant inicialment pels materials esmentats a l'aturada anterior. Tot així, immediatament hem entrat a la Depressió de Mora, $i$ hem trobat afloraments de materials cenozoics de l'Eocè i de l'Oligocè, fonamentalment de caràcter detrític. Per d'altra banda, molt sovint aquests materials es hem trobat recoberts per sediments detrítics quaternaris.

Així, en aquest indret, ens trobem situats dintre de la Depressió de Mora, $i$ apareixen potents sediments quaternaris, els quals cobreixen als sediments terciaris de l’Eocè i de l'Oligocè.

Cap al Nord d'on ara som, es veuen el relleus mesozoics de les Serres de Pàndols i Cavalls; així com els relleus de la Serra de Mora. Tots ells pertanyen a la denominada branca externa de la Serralada Prelitoral Catalana, que hem travessat al Pas de l'Ase. També es veuen, al peu de la Serra de Mora gruixos importants de sediments detrítics cenozoics, de l'Oligocè.

Per d'altra banda, al Sud d'on ara ens trobem es veuen els relleus mesozoics del Bloc de Cardó, que trobarem a Miravet. Aquests relleus formen part de l'anomenada branca interna de la Serralada Prelitoral Catalana.

Així, des d'aquest indret es veu clarament com unes $i$ altres estructures delimiten la depressió on ara estem situats, l'esmentada Depressió de Mora, situada entre la Branca Externa $i$ la Branca Interna de l'esmentada Serralada Prelitoral Catalana del Sistema Mediterrani. 


\section{PARADA 8. DIPÒSIT I CAP DE TIR, CARRETERA A FALSET, (terme municipal de Mora la Nova, comarca de la Ribera d'Ebre). (Full 471).}

Des de la parada anterior cal sortir de Mora la Nova per la carretera N-420, la que es dirigeix cap a Falset. Així, cal fer tota la pujada de la carretera, fins arribar quasi a la seva fi. Així, caldrà agafar un trencall que hi ha a la dreta, fins a uns 100 metres d'agafarla. En aquest indret, a uns $2 \mathrm{Km}$ de la parada anterior, en caldrà fer un altra.

Tot aquest recorregut s'haurà fet íntegrament per la Depressió de Mora; així, s' hauran anant tallant afloraments dels terrenys cenozoics que la reblen, tot i que sovint es troben recoberts per terrenys detrítics quaternaris.

Des d'aquest indret es pot fer una bona observació de l'esmentada Depressió de Mora, envoltada per la Branca Externa de la Serralada Prelitoral Catalana (situada al Nord) i per la Branca Interna de la Serralada Prelitoral Catalana (situada al Sud). Ambdues integrants del Sistema Mediterrani, a l'igual que la depressió que estem observant.

Des d'aquest lloc es pot veure els ventalls dels materials quaternaris. Aquests ventalls al·luvials procedeixen de la Serralada (especialment de la seva Branca Interna), i van avençant cap a la Depressió de Mora, tot formant uns interessants deltes. Aquests es fan força clars des del l'indret on som, tot mirant cap al Sud.

\section{PARADA 9. EL CONGOST DE MIRAVET, (terme municipal de Miravet, comarca de la Ribera d’Ebre). (Full 471).}

Des de la parada anterior cal tornar cap a Mora la Nova. Quasi en arribar-hi, es trobarà el trencall, des d'on es pot anar cap a la carretera C-12 (que ja havíem seguit abans), per tal de seguir-la tot anant cap al Sud. Així, aviat es deixarà per la dreta el trencall que se'n va cap a Tivissa. Més endavant es sobrepassarà el poble de Ginestar, que quedarà a la dreta. Més endavant s'arribarà al trencall d'on eix (per la dreta) la carretera que va cap al "pas de barca". Ens caldrà anar-hi, per de passar a l'altra banda del riu. Tot seguit, ens caldrà seguir per la carretera que es dirigeix cap a Miravet. En arribar a aquest poble podem fer una nova aturada, a la vora del riu Ebre. Així, des de la parada anterior, haurem recorregut uns $10 \mathrm{Km}$ més.

En aquest recorregut, hem anat circulant inicialment pels materials esmentats a l'aturada anterior, els quals pertanyen a la Depressió de Mora, a través de la qual hem anat fent tot aquest tram del recorregut.

En arribar a l'indret de l'aturada ens haurem trobat amb l'aflorament dels materials mesozoics del Juràssic i del Cretàcic, de caràcter eminentment carbonatat. Aquests materials constitueixen els relleus sobre els quals s'assenta el Castell Templari de Miravet, al que anirem després. Cal dir que formen part del Bloc de Cardó; és a dir: de la Branca Interna de la Serralada Prelitoral Catalana.

Precisament, el riu Ebre en travessar aquests materials (aiguies avall del poble) ha configurar el Congost de Miravet, un dels indrets importants del nostre Patrimoni Geològic. FOTOGRAFIA 3 


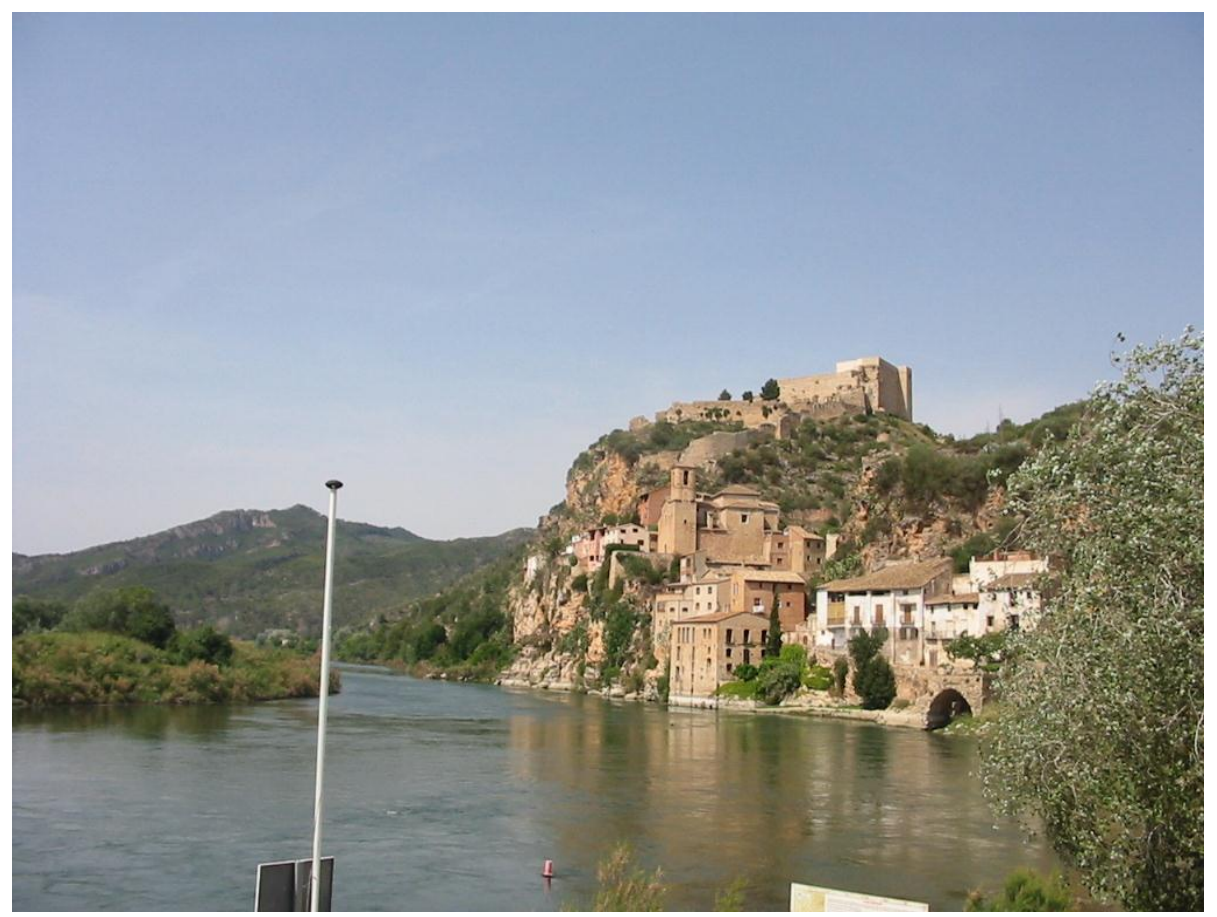

FOTOGRAFIA 3

Aspecte de Miravet, sobre l'aflorament de roques carbonatades mesozoiques del Bloc de Cardó

\section{EN AQUEST INDRET FINALITZA EL RECORREGUT DE L'ITINERARI}

\section{BIBLIOGRAFÍA}

GUIMERÀ, J. et altri (1992).- Geologia (II), Història Natural dels Països Catalans, Vol.2, 547 pag. Enciclopèdia Catalana, S.A. Barcelona

IGME (1974).- Mapa Geológico de España a escala 1:200.000. Sintesis de la Cartografia existente. Hoja y memória no 41 (Tortosa). Inst. Geol. Min. España. Minist. Indústria. Madrid

MATA-PERELLÓ, J.M. (1989).- Una recerca mineralògica per les terres de 1'Ebre: del Matarranya al Priorat. But. Col. Ofi, de Doctors i Llicenciats, nº 67, 15pag. Barcelona

MATA-PERELLÓ, J.M. (1991).- Els Minerals de Catalunya. Arxius de la Secció de Ciències, t. XCIII, 442 pag. Institut d'Estudis Catalans. Barcelona

MATA-PERELLÓ, J.M. (1995a.- Apunts per a un itinerari geològico-mineralògic entre Gandesa (Terra Alta) i Fuentes de Ebro (Ribera Baja de Ebro), Inèdit, 12 p. Manresa

MATA-PERELLÓ, J.M. (1995b).- Inventari Mineralògic de la comarca de la Ribera d’Ebre, Terra Endins, nº 9, 23 pag. Manresa 
MATA-PERELLÓ, J.M. (1995c).- Inventari Mineralògic de la comarca de la Terra Alta, Terra Endins, nº 10, 22 pag. Manresa

MATA-PERELLÓ, J.M. (1996).- Itinerari geològic i mineralògic entre Gandesa, la Fontcalda i Vall-de -roures. Inèdit., 12 pàgines. Manresa

MATA-PERELLÓ. J.M. (1997a).- Recerca geològica i mineralògica per les comarques de la Terra Alta i del Matarranya: des de Gandesa a Bot i Horta de Sant Joan, i des de Vallde-roures a Fondespatlla. Inèdit, 17 pàg. Manresa

MATA-PERELLÓ, J.M. (1997b).- Recerca geològica i mineralògica per les comarques del Priorat, de la Ribera d’Ebre, del Segrià i del Baix Cinca: des d'Ulldemolins a Flix i a Fraga. Inèdit, 14 pag. Manresa

MATA-PERELLÓ. J.M. (2000a).- Recerca geològica i mineralògica per les comarques de la Terra Alta i de la Ribera de 1'Ebre: des de Pinell de Brai i Prat de Compte a Gandesa i a Mora d'Ebre. Algeps, sèrie B, nº 171, 14 pàg. Manresa

MATA-PERELLÓ. J.M. (2000b).- Recerca geològica i mineralògica per les comarques de la Terra Alta i del Matarranya: des de Gandesa a Vall-de-roures i a Fondespatlla. Algeps, sèrie $B, \mathrm{n}^{\circ} 176,18$ pàg. Manresa

MATA-PERELLÓ, J.M. (2000c). - Recerca geològica i mineralògica per les comarques de la Ribera d’Ebre i del Priorat: des de Flix cap Ascó, el Molar i Mora. Inèdit. 11 pag. Manresa

MATA-PERELLÓ, J.M. (2001a). Recorregut de recerca geològica i mineralògica per les comarques del Baix Camp, de la Ribera d'Ebre i del Baix Ebre: des d’Hospitalet de 1'Infant al Perelló; i des de Rasquera a Mora la Nova i Ascó. Inèdit. 16 pag. Manresa

MATA-PERELLÓ. J.M. (2001b).- Recorregut de recerca geològica i mineralògica per les comarques de la Ribera d'Ebre i de la Terra Alta: des d'Ascó a Pinell de Brai, i des de Prat de Compte a Horta de Sant Joan, Inèdit, 18 pàg. Manresa

MATA-PERELLÓ. J.M. (2001c).- Recorregut de recerca geològica i mineralògica per les comarques de la Terra Alta i del Matarranya: des d’Horta de Sant Joan a Vall-de-roures i a Fontespatlla Inèdit, 18 pàg. Manresa

MATA-PERELLÓ. J.M. (2001d).- Recorreguts geològics i geonaturalistics pels Ports. Escola d'Estiu del Col.legi de Llicenciats, 75 pag. Manresa

MATA-PERELLÓ. J.M. (2006).- Recorregut geològic i miner per les comarques de la Ribera d'Ebre i Terra Alta: des d'Ascó a Mora d'Ebre, Miravet, Pinell de Brai, a Prat de Compte i a Bot. Inèdit. 16 pag. Manresa

MATA-PERELLÓ, J.M. i ARASA, A. (2004).- Recorregut geològic i miner per la comarca de la Terra Alta: des de Gandesa i el Pinell de Brai cap a Prat de Compte i Horta de Sant Joan Inèdit, 12 pag. Manresa 
MATA-PERELLÓ. J.M. (2006a).- Recorregut geològic i miner per les comarques de la Ribera d’Ebre i Terra Alta: des d'Ascó a Mora d’Ebre, Miravet, Pinell de Brai, a Prat de Compte i a Bot. Inèdit. 16 pag. Manresa

MATA-PERELLÓ. J.M. (2006b).- Recorregut geològic i miner per les comarques de la Ribera d'Ebre i Terra Alta: des de Vinebre a Mora la Nova, Miravet, Pinell de Brai i a la Fontcalda. Inèdit. 16 pag. Manresa

RIBA, O. et altri (1976).- Geografia Física dels Països Catalans, Edit. Ketres, 254 pàgines. Barcelona. 